\title{
An Investigation into English Mixing in Chinese Internet Language
}

\author{
Nick Zhiwei Bi \\ Faculty of Education and Social Work, University of Sydney \\ Sydney NSW 2006, Australia \\ Tel: 61-2-9351-2640Ｅ-mail: zhbi6097@uni.sydney.edu.au
}

$\begin{array}{lc}\text { Received: July 17, } 2011 & \text { Accepted: August 5, } 2011 \quad \text { Published: October 1, } 2011 \\ \text { doi:10.5430/wjel.v1n2p60 } & \text { URL: http://dx.doi.org/10.5430/wjel.vln2p60 }\end{array}$

\begin{abstract}
This paper examines the code-mixing phenomenon in Chinese internet language from top 10 websites. By analysing 250 code-mixing sentences, the study found most often used English words are NBA, love, CBD, flash, New etc. The semantic functions of these words are quite similar to research conducted in other contexts of Chinese cultural origin (e.g., Hong Kong and Taiwan). In addition, 200 questionnaires were sent out in order to better understand the general public's attitudes towards English mixing in Chinese internet discourse. The findings indicate that code-mixing is a trend in Chinese internet discourse, but there is not a sign of cultural invasion by those words because those words are purely having the linguistic function rather than other features. The study also suggests that though English mixing has become an inescapable trend, much attention still needs to be paid on how to balance the use of code-mixing, in order to make less confusion and refrain from cultural interference.
\end{abstract}

Keywords: Code-mixing, Chinese internet discourse, Cultural invasion

\section{Introduction}

Due to the notion and reality of globalization, English has spread as a medium of global transaction and has become a truly global language. Irrespective of how well-established and well-protected local cultures are, the world has been linguistically dominated by English. Chinese is not an exception either, though having kept its own feature and integrality for more than 5000 years, the old character based Chinese language system compared with simple Latin alphabet English language is facing many challenges. The emergence of English words in Chinese has been so fast that official statistics indicate about 1,000 such new words are added to the Chinese vocabulary each year (Xing, 2004). In 2010, the Chinese government announced a new policy prohibiting the use of English language in various media to keep the Chinese 'pure'; however, insofar, no proper study has been conducted to prove whether this protection is good or will result in more problematic consequences in mainland China. Therefore research on this issue seems to be very necessary and urgent. In other countries, a number of researchers (Vestergaard \& Schrøder1985; Cook, 1992; Bruthiaux, 1996; Goddard, 1998; Li, 1996, 2000; Chen, 2006) have paid their attention to language mixing in press advertising. However, the research was mainly focused on western media and little research has been done in Chinese context, especially in Chinese internet language. This study therefore attempts to investigate the internet language from website news, internet advertisement and Web log (blog) to find out the most frequently mixed English expressions based on the framework of Chen's (2006) research on English mixing in Taiwanese magazine advertisement. By using the major methodology from Chen's study, the study aims to improve the understanding of the most up-to-date information on English language used in Chinese mainland local media. The aim of this paper is to illustrate how and why those words are used in local language. Additionally, a questionnaire to examine public attitudes towards this phenomenon was conducted, aiming to provide a general attitude from the public and help to better understand the status quo of English 'invasion' in China.

\section{Literature Review}

\subsection{What is code-mixing (CM)?}

This term is usually used in the area of studying on bilingualism. Hamers and Blanc (1989, p.35) define that mixing usually involves the use of elements from language B in an utterance in language A (code-mixing, $\mathrm{CM}$ ) as well as the alteration between language A and Language B in the same utterance (code-switching, CS). In their book, CM is defined as 'an integral part of bilinguistic development. The majority of mixings are lexical in nature and nouns are most often substituted words (Hamers \& Blanc, 1989, p.35). In addition, there are some arguments about the distinctions between 
CS and CM (Chen, 2006). This paper will not join the debate. The study will use the term CM for all the mixed English language in Chinese internet, which is based on Chen's definition of CM, 'the intrasentential use of two or more languages or varieties of language' (Chen, 2006, p.467)

\subsection{What is mixed?}

In terms of $\mathrm{Li}$, 'a more psychological than physical concept is one of the crucial factors behind the bilingual's code-switching behaviour' (1996, p.46). Among them, topics like family, school, work places are most often talked about ( $\mathrm{Li}, 1996)$. He also indicates that the phenomenon of CM or CS is mainly because of 'culture or specific vocabulary in the guest language' ( $\mathrm{Li}, 1996, \mathrm{p} .47)$. Also, young people get used to talk about topics like pop music, fashion, and politics in a code-mixing way, because Chinese equivalents are not specialized enough (Kwok \& Chan, 1972).

\subsection{Where is CM?}

CM becomes very popular in many fields. It is not only a concept debated in bilingualism, but in computer, business, fashion industry, food discourse, showbiz, and our daily life, there are a huge number of code-mixings existing. The most popular focuses of this topic in China are still on traditional media like newspapers, TV, magazine, radio etc (Li, 2000) and medium of instruction in English class (Wu, 1985).

\subsection{Why CM is used?}

As mentioned above, the use of CM usually has its specific reason and many researchers have already concluded some functions of code-mixing. Wu identifies three functions of $\mathrm{CM}$ in her study of examining $\mathrm{CM}$ in bilingual English teachers of China:

(1) To achieve ease of expression;

(2) To achieve expressiveness and simplicity, and

(3) To produce rhetorical effects (e.g. Hi - fi, jet -lag, skydive)' (1985, p.314)

From her propositions, it is clear that CM is common and useful, sometimes adopting directly from the source language is more effective way rather than looking for exact equivalents in target language.

The study (Li, 2000) on CM in Hong Kong is another important research on code-mixing in Chinese language, he also summarises four motivations of code mixing:

(1) Euphemism: It is embarrassing to mention some words in Chinese culture. Therefore, if using the English version, it will make the speaker or the listener more comfortable to accept it.

(2) Specificity: Compared with its Chinese equivalents, English words are more specific.

(3) Bilingual punning: In terms of $\mathrm{Li}$, another important motivation of code-mixing is to produce a double meaning with the English words

(4) Principle of economy: Li also highlights in his study that English is preferred because it has simple structure and is less time-consuming to remember compared with its Chinese equivalents.

Most recently, Chen's study (2006) on advertising media in Taiwan draws some conclusions that code-mixing often 'carries extra sociopragmatic meaning such as attention, modernization, and creativity' (p. 477). He also suggests that in a few years time, it is hard to find an advertisement without English in it. Lau (2007) investigates code-mixing in Chinese business advertisements in Malaysia. The study found that English nouns appear most frequently in Chinese business advertisements. Some English verbs are deliberately put into the advertisements to make it modern and young. English abbreviations are used for simpler and shorter purposes. Lau et al (2011) again gathered the similar results by analysing entertainment news of Chinese newspaper in Malaysia. In addition, the study also found some incorrect usage of English grammar in Chinese entertainment news and some words also change their functions when mixed in the Chinese news.

As noted above, there are a number of studies on English mixing in various Chinese-speaking contexts; however, as English mixing is a controversial topic in mainland China, little research has been done in this largest Chinese-speaking country, whereas, English mixing seems to appear in every aspect of mainland Chinese media. Internet language in particular, because of its fast, convenient and lack of supervision nature, quite a number of English words can be found mixing in Chinese internet news headings, advertisements, blogs etc. Due to lack of research on code-mixing in internet language, and especially the English mixing phenomenon in the media of mainland China, it seems that such a study is necessary to be conducted. Those findings from previous studies in other Chinese-speaking regions can also provide a 
better understanding of why and how English words are used in mainland Chinese internet language. Also, the existing research is a good reference for this study to examine whether findings are consistent with the previous results.

\section{Research Methodology}

A small corpus (see Appendix 2) which contains data from 10 most influential Chinese websites is created. Ten websites are selected by surveys and public recognitions, most of which are ranked top 10 websites in China (CERN, 2001). For instance, CCTV (China Central Television) is the website of the largest TV channel in China and Xinhua is the news website for Chinese government. Both are usually regarded as representing the voice of government. Therefore, those selected websites are most frequently visited by Chinese internet users or considered to be the most influential ones.

Data was collected by viewing the detailed news, advertisements and blogs of each website and then 258 English expressions were found in $200 \mathrm{CM}$ sentences from those websites. The data collections avoided recording English brand names and company names, because they are just the common names or simple abbreviations, and they would not be considered as CM in this paper. The words and expressions selected were directly from news titles, sentences from latest news contents, internet advertisements, and blogs. The data was collected randomly without any bias or preference.

\section{Results and Data Analysis}

It is worth noting that most of the words are actually abbreviations and nouns (like NBA, CBD, TV, see Table 1), which are consistent with the propositions that the majority of mixings are lexical in nature, nouns are most often substituted words (Hamers \& Blanc, 1989, p.35). The pattern of top ten words is also similar to Chen's (2006) research. However, there are also some special internet dictions which are rarely seen in other media, such as blog, BBS, e- etc. However, unfortunately, expressions which produce rhetorical effects (Wu, 1985, p.314) were not found in Chinese websites.

$<$ Table 1 about here $>$

The most often used English words (See Table 1) include many abbreviations which are not traditionally recognized English words. However, the study found that some nouns, adjectives, verbs, even interjections are also used in Chinese media (See Appendix 2). According to Li's four functions of code-mixing, those words can be simply identified into each category.

Firstly, expressions like ML (abbreviation of making love) are taboo topics in public place in China. People always feel ashamed when talking about their personal life. Hence, if directly using English words to express the same ideas, people will feel more natural or easy to accept it. This study found that there are many such words and expressions Chinese having adopted from English, such as sex, gay, bra, etc. Those topics sound less embarrassing or more acceptable if using their English words.

Secondly, words and expressions like e-, top, are more specific than their Chinese equivalents. 'e-' is the usage for describing electronic products or phenomenon, like e-tool, e-commerce, e-bay, e-learning. Adopting the English expression directly not only makes the expression more tidy, but also more precise. Top plus numbers usually refers to a particular ranking. For instance, we have top 20 pop music ranking, top 50 universities, top 50 places to visit, etc. Furthermore, it is hard to find an exactly precise and accurate equivalent in Chinese language. Therefore, direct use of English expressions here seems very appropriate.

Thirdly, words like 'wow' and 'bye' have the similar meaning to Chinese words. 哦(Oh), 拜拜(bai bai). The adoption of such English words or expressions may simplify the complexity of writing Chinese characters and make the sign clearer for the familiar users, because two English words not only have exactly the same meaning with Chinese words, but also have the similar pronunciation. Chinese internet users have no difficulties in understanding these simple short words. In websites, many sentences start with 'Wow' to express a surprising or happy mood, and it has a great effect of bilingual punning. .

Finally, the most common reason for CM is the principle of economy ( $\mathrm{Li}, 2000)$ or ease of expression (Wu, 1985). These kinds of words are the most often used in other media as well, because they are the original English abbreviations. More and more media and even official text books have used this kind of code-mixing. NBA which is the abbreviation of 'National Basketball Association' appears most frequently than any other words in this corpus. Instead of writing it in the form of Chinese character '美国职业篮球联赛', nearly all the websites refer it to its English Abbreviation. It really fulfils the function talked above, making the expression much easier and more expressive. Actually those words are most often used in this manner to make the language much simpler as well as to avoid inaccurate translation. 


\section{Discussion}

According to the analyses above, it can be noted that there is a clear trend of CM in Chinese internet language. However, Chinese is still the unmarked and normative choice of Chinese internet language, whereas, English has already embedded into it. CM phenomenon appears in all ten websites.

The function of English code-mixing is very straightforward, and there is no evidence of cultural invasion or impurity from the meaning of those English words. The main function of code-mixing here is to attract audience, ease the expression and promote a sign of modernization. From various examples, it can be seen that English abbreviations are used very frequently in those websites. Most of them are noun expressions (67.82\%), but some word classes like adjectives (11.6\%), interjections (3.1\%) and verbs (13.57\%) are also seen there. See Table 2.

$<$ Table 2 about here $>$

\subsection{Data}

Another interesting finding is that $\mathrm{CM}$ sentences appear far more often in top ten commercial websites than those so-called government controlled websites. For instance, in Xinhuanet.com, only 2 English abbreviations (CNN, CPI) are found in this website. In China's national TV channel website, the situation is quite similar. Therefore, it can be concluded that in China, the government or quasi-government bodies still try to keep the integrality of Chinese language and avoid using English words.

Finally, more and more English words are used in Chinese websites, and it has become an unavoidable trend. In some commercial websites like qq.com and sohu.com, the CM sentences are very easy to be found. The reason why those English words are widely used may attribute to the strategy of attracting young users.

\subsection{Questionnaires}

200 Questionnaires (see Appendix 3) were sent out in order to better understand the general public's attitudes towards English mixing in Chinese internet language (Items include: participants' basic background information and general attitudes towards this phenomenon, and a likert-scale questionnaire).

Finally, only 190 valid questionnaires were collected. Among the 190 participants 115 are females, 75 are males. Most of them are students aged between 18 and 28. The general attitudes (see Figure 1) from them are positive and $77.5 \%$ of the participants show very positive attitudes towards CM in Chinese internet language, while $16.25 \%$ showed very negative attitudes. Negative attitudes are higher than Chen's research in Taiwan. The reason may differ from social cultural system between mainland China and Taiwan.

$<$ Figure 1 about here $>$

From the likert-scale questionnaire, it is found that those expressions are very simple, popular and fashionable expressions both in English speaking countries and worldwide. Words and expressions are purely adopted due to its semantic features, $78 \%$ of the participants said that there are no difficulties in understanding them. Furthermore, CM expressions used in various media, words or expressions are sometimes very informal, ungrammatical or not officially recognized in Chinese language, a large number of adoptions may impurify Chinese language. $85 \%$ agreed that there should be a regulation to supervise this phenomenon. Secondly, most respondents (95\%) agreed that it may leave the monolingual speakers to disadvantage positions. Though the amount of mixing expressions is only some words which are semantically easy in contrast to numerable English vocabulary, monolinguals in China still take up the majority of population, especially for elderly people and low-educated people, it may result in big obstacles in understanding. Thirdly, a large number of participants (95\%) also agreed that CM is the major reason of Chinglish or China English. CM phenomenon may also make Chinese language become English-styled (Li, 1996, p.141). Zhou and Feng (1987) make use of the term 'Englishization' to describe the influence of English on written Chinese in mainland China at lexical, phonological, syntactic and semantic levels. The prefix mini, for example, has already become a Chinese word now, and this research also found that some examples to prove that. Some participants $(38.5 \%)$ also agreed with the notion that if CM keeps evolving, it is likely to produce a Pidgin English in China (also see, Xing, 2004; Yun \& Jia, 2003).

\section{Limitations of the Study and Future Research}

Due to the scale of this study, only small amount of data was examined, and the research and conclusion were only based on the investigation itself. In future study, more data should be collected to make the study more convincing and generalisable. Another shortage of this research is that there are no comparisons with other media. Therefore, the 
research data can only represent the $\mathrm{CM}$ in internet language, future studies may focus on analysing whether different media have different CM words or play different functions. Also, the internet users are predominantly young people in China. In future studies, CM in different age group may be one aspect to consider. In addition, the paper mainly focuses on primary linguistic factor, while addresses less attention to macrolinguistic factors, which involves issues like acculturation and biculturalism (Kachru, 1983). It may also be a very important area to investigate in order to reveal the external reasons of $\mathrm{CM}$ in Chinese media.

\section{Conclusion}

Internet has become the most popular media among Chinese people, and CM phenomenon also frequently happens in this new media. Though Chinese language is still the predominant pattern in internet language, the mixing use of English words in websites has become an unavoidable trend. In this study, it is found that the wide use of English words in Chinese media is quite popular, and the main function is to attract audience, avoid embarrassing topic, simplify and specify particular terms or words, most importantly to ease the expression of the equivalent Chinese language. However, there are also many adverse impacts of English code-mixing in China now. Wide adoption of those English words may impurify Chinese language and make confusions among different users, and it will also produce more inappropriate or non-standard English and non-standard Chinese expressions. Though there are many criticisms, even the Chinese government has made a law to prevent English impurifying Chinese language, in the near future code-mixing may still happen much more often in different Chinese media due to various reasons discussed in this study. Therefore, more future studies are needed to pay closer attention to this phenomenon and ensure the development of code-mixing is healthy and keeps balanced with Chinese language.

\section{References}

Bruthiaux, P. (1996). The discourse of classified advertising: exploring the nature of linguistic simplicity. Oxford: Oxford University Press.

Chen, Cheryl, W. Y (2006). The mixing of English in magazine advertisement in Taiwan. World Englishes. 3 (4), 467-478. http://dx.doi.org/10.1111/j.1467-971X.2006.00467.x

Cook, G (1992). The language of advertising. ( $2^{\text {nd }}$ ed.). London: Routledge.

Goddard, A. (1998). The language of advertising: written texts. ( ${ }^{\text {nd }}$ ed.). London: Routledge.

Hamers. J. F. \& Blanc, M. H. A. (1989). Bilinguality and bilingualism. Cambridge: Cambridge University Press.

Kachru, B. (1983). The Indianziation of English: The English language in India. Delhi: Oxford University Press.

Kwok, H. \& Chan, M. (1972). Where the twain do meet. General linguistics. 12(2), 62-82.

Lau, S. K. (2007). Fenomena Percampuran Kod dalam Iklan Perniagaan Bahasa Cina di Malaysia. Unpublished Research Report of Master of Modern Language Studies. University of Malaya, Faculty of Language and Linguistics.

Lau, S. K.; Cheng, X.; Yee, T. K. \& Ling, C. W. (2011). Code-mixing of English in the entertainment news of Chinese newspaper in Malaysia. International Journal of English linguistics. 1(1), 3-14.

Li, David C. S. (1996). Issues in bilingualism and biculturalism: A Hong Kong case study. New York: Peter Lang Publishing, Inc..

Li, David C. S. (2000). Cantonese-English code-switching research in Hong Kong: a Y2K review. World Englishes. 19(3), 305-322. http://dx.doi.org/10.1111/1467-971X.00181

China Education and Research Network (CERN) (2001). Top 100 Chinese Websites. [Online] Available: http://www.edu.cn/20010101/22272.shtml (Oct 1, 2009).

Vestergaard, T. \& Schroder, K (1985). The language of advertising. Oxford: Blackwell.

Wu, Y. A (1985). Code-mixing by English-Chinese bilingual teachers of the People's Republic of China. World Englishes. 3(4), 303-317.

Xing, Z. G (2004), Purity of Chinese language debated. China daily. Sep 13, 2004.

Zhou, Z. P. \& Feng, W. C (1987). The two faces of English in China: Englishization of Chinese and nativization of English. World Englishes. 6(2), 111-125. http://dx.doi.org/10.1111/j.1467-971X.1987.tb00186.x 
Table 1. Top ten most often used English words

\begin{tabular}{|l|c|c|}
\hline English Words & Times of Appearance & Percentage \\
\hline NBA & 15 & 5.81 \\
\hline TV & 14 & 5.43 \\
\hline CBD & 11 & 4.26 \\
\hline MP3 & 11 & 4.26 \\
\hline FLASH & 9 & 3.5 \\
\hline BLOG & 9 & 3.5 \\
\hline BBS & 9 & 3.5 \\
\hline CPI & 4 & 1.55 \\
\hline IT & 3 & 1.16 \\
\hline NEW & 3 & 1.16 \\
\hline Total & 88 & $34.13 \%$ \\
\hline
\end{tabular}

Table 2. Syntactic categorization of the English expressions

\begin{tabular}{|l|l|c|c|}
\hline Syntactic categories & Examples from the Corpus & Number of Occurrences & Percentage \\
\hline 1. Noun phrases & Info, Blog, ML & 175 & $67.82 \%$ \\
\hline 2. Adjective Phrases & Free, New & 30 & $11.6 \%$ \\
\hline 3. Use of English Alphabet & E- & 5 & $1.93 \%$ \\
\hline 4. Verb phrases & Update, Look & 35 & $13.57 \%$ \\
\hline 5. Interjections & Oh, bye, Wow & 8 & $3.1 \%$ \\
\hline 6. Clauses & Life sucks/Life is not easy & 3 & $1.2 \%$ \\
\hline 7. Adverbial phrases & Anyway & 1 & $0.39 \%$ \\
\hline 8. Conjunction & And & 1 & $0.39 \%$ \\
\hline Total & & $\mathbf{2 5 8}$ & $\mathbf{1 0 0 \%}$ \\
\hline
\end{tabular}

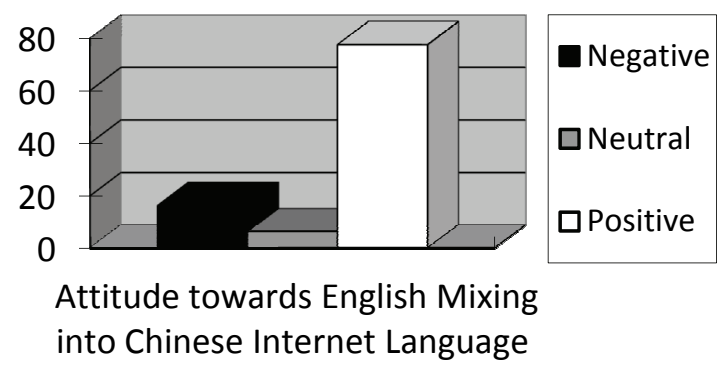

Figure1. Attitudes from general public towards CM

Appendix 1: Some selected code-mixing sentences

(1) 订阅更多动画 flash, 给你不一样的精彩。(Advertisement) www.qq.com (Pinyin: Ding yue geng duo dong hua flash, gei ni bu yi yang de jing cai) (English translation: Subscribe to more animation flash, it will give you different excitement)

（2）超级女什么虽不很专业，但征服无数 fans 的声音也将在长久回荡在互联网间。(News) www.qq.com (Pinyin: chao ji nv sheng sui bu hen zhuan ye, dan shi zheng fu le wu shu fans de sheng yin ye jiang zai chang jiu hui dang zai hu lian wang jian) (English Translation: Though Super girls are not professional singers, innumerable fans have already been conquered and their song will be heard on internet for a long time.) 
(3) NBA 里面没有神! 如果有, 邓肯将是不被遗忘的神。(News) www.sohu.com (Pinyin: NBA li mian mei you shen! $\mathrm{Ru}$ guo you, deng ken jiang shi bu bei yi wang de shen) (English Translation: There is no god in NBA, if there is, Duncan will be the one not forgotten forever.)

（4）七成网友跟恒源祥说 bye bye。 (News Title) www.sina.com.cn (Pinyin: qi cheng wang you gen heng yuan xiang shuo bye bye.) (English Translation: 70\% people said bye bye to Heng Yuan Xiang (a clothing Manufacturer).

(5) 新歌 top500, 难忘老歌 top500。 (Website homepage Title) www.yahoo.com.cn (Pinyin: xin ge top500, nan wang lao ge top500) (English Translation: here is new song top 500, unforgettable old song top 500)

(6) 格调 new 街区 特价底商限量发售。(Advertisement) www.163.com (Pinyin: ge diao new jie qu, te jia di shang xian liang fa shou) (English Translation: New pattern of blocks (means real estate), special price until sold out.)

(7) 中意 mini 豪华轿车。(Advertisement) www.sohu.com (Pinyin: zhong yi mini hao hua jiao che.) (English translation: Having affections to mini luxury sports car.)

(8) 女人第一次和男人 ML 的感觉。(Blog) www.baidu.com (Pinyin: nv ren di yi ci he nanren $\boldsymbol{M L}$ de gan jue) (English Translation: Women's feeling to make love with a man for the first time.)

(9) Life is not easy. 我们只有勇敢地面对, 坦然地承受, 豁达地接受, 乐观地反省. (blog) www.baidu.com (English Translation: Life is not easy. I have to face it courageously, bear it magnanimously, accept it easily, reflect it optimistically.)

(10)Look 漫画喽! (Blog） www.chinaren.com (Pinyin: Look man hua lou!) (English Translation: Look comic books ah!)

Appendix 2: List of CM expressions in Chinese internet language corpus

\begin{tabular}{|c|c|}
\hline $\begin{array}{l}\text { 1. Noun phrases } \\
(175)^{*}\end{array}$ & $\begin{array}{l}\text { NBA (15), TV (14), CBD (11), MP3 (11), flash (9), BBS (9), CPI (4), IT (3), F1(2), ML(2), fans (2), } \\
\text { HR (2), MV (2), Olympics (2), CNN (2), Info (2), GPS (2), CEO (2), USB (2), DJ (2), offer (2), } \\
\text { order (2), CD (2), meeting (2), sex (2), city (2), stress (2), paper (2), school (2), holiday (2), Hi-Fi } \\
\text { (2), facebook (2), DVD (2), fish (2), chips (2), pizza (2), MSN (2), exam (1), period (1), case (1), } \\
\text { medicare (1), management (1), size (1), expiry (1), chapter (1), season (1), bank (1), research (1), } \\
\text { family (1), trainer (1), resume (1), game (1), heater (1), traffic (1), expo (1) lecture (1), party (1), } \\
\text { takeaway (1), training (1), interview (1), report (1), proof (1), background (1), movie (1), superhero } \\
\text { (1), assignment (1), food (1), mood (1), gay (1), destination (1), workshop (1), suburb (1), mail (1), } \\
\text { coffee (1), effect (1), effect (1), book (1), bus (1). }\end{array}$ \\
\hline $\begin{array}{l}\text { 2. Verb phrases } \\
\text { (35) }\end{array}$ & $\begin{array}{l}\text { update (2), look (2), download (2), take care (2), go (2), pass (1), do (1), make (1), refund (1), review } \\
\text { (1), check (1), shut up (1), talk (1), borrow (1), destroy (1), send (1), return (1), consult (1), love (1), } \\
\text { Practice (1), know (1), study (1), cook (1), read (1), fix up (1), cover (1), interrupt (1), catch (1), } \\
\text { ignore (1), copy (1). }\end{array}$ \\
\hline $\begin{array}{l}\text { 3. Adjective } \\
\text { Phrases (30) }\end{array}$ & $\begin{array}{l}\text { new (3), free (2), good (2), bad (2), nice (2), cool (2), mini (2), long (1), big (1), credit (1), high (1), } \\
\text { extra (1), basic (1), special (1), ready (1), quick (1), top } 100(1) \text {, fast (1), standard (1). lucky (1), easy } \\
\text { (1), funny (1). }\end{array}$ \\
\hline $\begin{array}{l}\text { 4. Use of } \\
\text { English } \\
\text { Alphabet (5) }\end{array}$ & e- $(5)$ \\
\hline $\begin{array}{l}\text { 5. Interjections } \\
\text { (8) }\end{array}$ & oh (2), bye (2), wow (1), but (1), yes (1), ok (1). \\
\hline 6. Clauses (3) & $\begin{array}{l}\text { Life is not easy. (1); } \\
\text { I love you. (1); } \\
\text { Who knows? (1). }\end{array}$ \\
\hline $\begin{array}{l}\text { 7. Adverbial } \\
\text { Phrases (1) }\end{array}$ & anyway (1). \\
\hline $\begin{array}{l}\text { 8. Conjunction } \\
\text { (1) }\end{array}$ & and (1). \\
\hline Total & 258 \\
\hline
\end{tabular}

* The numbers in the bracket indicate number of occurrences of each expression 
Appendix 3: Attitude towards English Mixing in Chinese Internet Language Questionnaire

Age Group: 15-25 $35-45$

Gender: Male
25-35

45 or above

Your Education Backgrounds: High School or below

Vocational Education

Undergraduate

Postgraduate

Questions:

1. What is your attitude towards English Mixing into Chinese Internet Language?

Positive

Negative

Neutral

2. How often you use internet in a week?

Less than 1 day

1 day to 4 days

4 days to 6 days

Every day

3. Circle the response for each of the following items

\begin{tabular}{|c|c|c|c|c|c|}
\hline & $\begin{array}{l}\text { Strongly } \\
\text { Agree }\end{array}$ & Agree & Neutral & Disagree & $\begin{array}{l}\text { Strongly } \\
\text { Disagree }\end{array}$ \\
\hline $\begin{array}{l}\text { 1.Providing opportunities to } \\
\text { learn English }\end{array}$ & & & & & \\
\hline 2.English is linked to daily life & & & & & \\
\hline $\begin{array}{l}\text { 3.You find the English words } \\
\text { easy to understand }\end{array}$ & & & & & \\
\hline $\begin{array}{l}\text { 4.It is a sign of } \\
\text { internationalisation/globalisation }\end{array}$ & & & & & \\
\hline $\begin{array}{l}\text { 5.It draws your attention when } \\
\text { seeing English mixing } \\
\text { languages }\end{array}$ & & & & & \\
\hline $\begin{array}{l}\text { 6. You find the English easy to } \\
\text { understand }\end{array}$ & & & & & \\
\hline $\begin{array}{l}\text { 7. You think CM is the main } \\
\text { reason of Chinglish and Chinese } \\
\text { Englishlisation }\end{array}$ & & & & & \\
\hline $\begin{array}{l}\text { 8.You think it will 'impurify’ } \\
\text { Chinese Language }\end{array}$ & & & & & \\
\hline $\begin{array}{l}\text { 9. It may make monolinguals } \\
\text { disadvantaged }\end{array}$ & & & & & \\
\hline $\begin{array}{l}\text { 10. There should be a regulation } \\
\text { to supervise this phenomenon }\end{array}$ & & & & & \\
\hline $\begin{array}{l}\text { 11. There will be a new pidgin } \\
\text { English in China due to CM }\end{array}$ & & & & & \\
\hline $\begin{array}{l}\text { 12. You will continue to read and } \\
\text { write in this way }\end{array}$ & & & & & \\
\hline
\end{tabular}

